\title{
Влияние катализирующих добавок на процесс получения углеродных сорбентов из отходов древесностружечных плит
}

\author{
(C) 2021 Глушанкова И.С., Атанова А.С. \\ Пермский национальный исследовательский политехнический университет, Пермь
}

Поступила в редакцию 15.01.2021 г.

DOI: $10.17308 /$ sorpchrom.2021.21/3472

В работе представлены результаты исследований, которые посвящены вопросам переработки много тоннажных полимерных отходов древесно-стружечных плит (далее ДСП) методом низкотемпературного пиролиза в присутствии катализирующих добавок: солей переходных металлов $\left(\mathrm{Cu}^{+}\right.$, $\mathrm{Ni}^{2+}$ ) и гидроксида калия. В работе проведен анализ научно-технической информации известных методов переработки полимерных отходов и способов получения углеродных сорбентов с применением различных реагентов. Целью настоящей работы являлось исследование влияния катализирующих добавок солей переходных металлов $\left(\mathrm{Cu}^{+}, \mathrm{Ni}^{2+}\right)$ и гидроксида калия на физико-химические, сорбционные и текстурные характеристики пиролизатов, полученных из полимерных отходов ДСП.

В работе авторами представлены результаты лабораторных исследований с применением современных аналитических методов измерений и оборудования. Анализ пористой структуры пиролизатов выполнен с использованием анализатора сорбции газов Quantachrome NOVA 4200e адсорбцией азота $(77 \mathrm{~K})$. Содержание валовых форм металлов определяли атомно-абсорбционным методом на пламенном атомно-абсорбционном спектрофотометре КВАНТ-2МТ по методике М-02Вд/2001. Методом рентгеновского микроанализа на сканирующем электронном микроскопе Hitachi S-3400N (Япония), который оснащен рентгеновским энергодисперсионным спектрометром NORAN, получены снимки при увеличении х1000. Также для исследований использованы стандартные методики, принятые в адсорбционной технике: спектрофотометрические, титриметрические, потенциометрические и др. Представлены результаты термохимической утилизации полимерных отходов ДСП, где установлены параметры процесса пиролиза. Оптимальное массовое соотношение отходов ДСП: катализатор 1:0.02, температура проведения пиролиза $600-700^{\circ} \mathrm{C}$, со скоростью 10-12 град/мин, время выдержки 30-60 мин. В работе исследовано влияние условий проведения пиролиза в присутствии КОН и без него на формирование пористой структуры и сорбционных свойств полученных образцов. Максимальный практический выход определен у образца ДСП:КОН (1:0.02) - 34\%, Сорбционные характе-

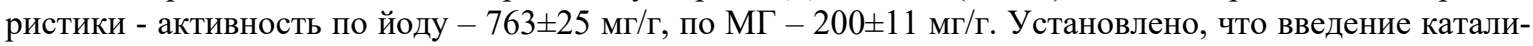
заторов влияет на практический выход, сорбционные свойства и параметры пористой структуры. Так, добавление катализаторов в систему $\mathrm{Cu}^{+}$и $\mathrm{Ni}^{2+}$ позволило увеличить выход продукта с 20 до $25 \%$. Введение в систему никелевого катализатора ДСП: $\mathrm{Ni}^{2+}(1: 0.02)$ позволяет увеличить сорбционную активность пиролизатов по йоду на $40 \%$. Объем микропор составляет $-0.203 \mathrm{~cm}^{3} / \Gamma$, площадь поверхности микропор - $562 \mathrm{~m}^{2} /$ г. С помощью сканирующей электронной микроскопии показано, что пиролизаты без катализаторов имеют слоистую упорядоченную структуру, схожую по своим свойствам с древесиной, размер пор составляет 10-50 нм. После введения катализаторов наблюдается нарушение структуры углей, в образцах ДСП: $\mathrm{Ni}^{2+}(1: 0.02)$ и ДСП: $\mathrm{Cu}^{2+}(1: 0.05)$ формируются более мелкие поры неправильной формы от 2.5 нм.

В результате проведенных исследований можно сделать вывод, что введение катализирующих добавок солей переходных металлов $\left(\mathrm{Cu}^{1+}, \mathrm{Ni}^{2+}\right)$ и гидроксида калия влияет на физикохимические свойства, пористую структуру пиролизатов и их текстурные характеристики. Предложенный способ позволяет получать пиролизаты в одну стадию, которые обладают сорбционными свойствами, близкие по характеристикам с промышленными марками древесных углей типа БАУМФ.

Ключевые слова: отходы древесностружечных плит, каталитический пиролиз, катализаторы, пористая структура, электронно-микроскопический анализ, пиролизаты. 


\section{Введение}

В последние десятилетия наблюдается рост производства и потребления композиционных материалов, и как следствие, образование и накопление полимерных отходов. К крупнотоннажным полимерным отходам относятся отработанные изделия из древесностружечных плит (далее ДСтП), которые широко используются в строительной отрасли при изготовлении мебели, дверей, стеновых панелей, балок и др. Согласно статистическим данным в России в 2019 г. изготовлено более 10 млн. м ${ }^{3}$ ДСтП [1].

Древесностружечные плиты представляют собой композиционные материалы, получаемые из отходов деревообрабатывающей промышленности (высушенной технологической щепы, опилок, стружки) методом прессования со связующими, в качестве которых используют фенолформальдегидные, карбамидоформальдегидные и карбамидные смолы. Среднее содержание связующего составляет 11-15 масс.\% от массы изделия.

В настоящее время основным методом утилизации крупногабаритных отходов ДСтП в России остается складирование их на полигонах твердых коммунальных отходов (ТКО), где в течение длительного времени протекают процессы химической, фотолитической и биохимической деструкции отходов, сопровождающиеся эмиссиями токсичных соединений (формальдегид, фенол, ацетон и др.) в объекты окружающей среды. В этой связи возникает необходимость разработки новых эффективных технологий их утилизации, позволяющих не только сократить объемы отходов, поступающих на полигоны ТКО, но и максимально использовать ресурсный и энергетический потенциал [2].

Анализ научно-технической информации показал, что проведение комплексной утилизации полимерных отходов ДСтП возможно методами вторичной переработки с получением товарных продуктов и термическими методами $[3,4]$.

Известны методы переработки отходов ДСтП с получением древесноугольных брикетов арболитовых панелей, опилкобетона. Однако работа с материалами на основе отходов ДСтП сопряжена с повышенным риском из-за выделения токсичных веществ. Высокая стоимость переработки, снижение эксплуатационных характеристик часто делает вторичные материалы на основе отходов ДСтП неконкурентоспособными по сравнению с изделиями, изготовленными из природного сырья. Кроме этого получаемые материалы должны пройти проверку на токсичность и иметь необходимые сертификаты качества $[5,6]$.

Отходы ДСтП обладают высоким энергетическим потенциалом, что обусловливает возможность применения методов сжигания и пиролиза для их утилизации. Сжигание как метод комплексной переработки многотоннажных крупногабаритных отходов с целью получения энергии не находит широкого применения из-за дорогостоящего оборудования, высоких эксплуатационных, энергетических затрат, необходимости глубокой очистки отходящих газов от токсичных примесей.

При низкотемпературном пиролизе углеводородсодержащих отходов (400$600^{\circ} \mathrm{C}$ ) в отсутствие кислорода протекают процессы деструкции отходов, сопровождающиеся карбонизацией и образованием пиролизных газов. Достоинством способа является возможность проведения процесса в автотермическом режиме, т.к. образующиеся пиролизные газы обладают высокой теплотворной способностью (30-35 МДж/кг) и могут быть использованы в качестве топлива для поддержания температуры в печи пиролиза. В результате термической переработки образуется углеродистый остаток - карбонизат, который в зависимости от свойств перерабатываемого отхода может обладать адсорбционными 
свойствами или служить сырьем для получения активированных углей.

Известно, что одним из способов управления процессом пиролиза твердых и жидких углеводородов является введение в систему каталитических добавок. Присутствие катализатора позволяет снизить температуру процесса, изменить механизм термохимической деструкции материалов и, соответственно, выход пиролизных газов и карбонизата [7].

Применение технологии каталитического пиролиза позволяет утилизировать трудно перерабатываемые компоненты полимерных отходов. Газообразные и жидкие продукты термохимического разложения потенциально могут быть использованы как энергоносители для получения тепловой энергии, карбонизат - в качестве сорбентов и компонентов смазок, пропиток, защитных составов [8].

Известны технологии каталитического пиролиза полимерных отходов с использованием в качестве катализаторов природных или синтетических алюмосиликатов. В работе Rehan M., Nizami A. S. и др. [9] исследован процесс пиролиза отходов полистирола, полиэтилена в присутствии модифицированных природных алюмосиликатов. Показано, что проведение низкотемпературного каталитического пиролиза полистирола, полиэтилентерефталата, полипропилена позволяет получить высококачественное жидкое топливо, а также увеличить выход карбонизата с 6-10\% до 30-40\%.

В качестве катализаторов процесса пиролиза полимеров также используются соединения переходных металлов подгруппы железа, импрегнированные в матрицу носителя [10-14].

В патенте РФ 2617213 авторами показано, что проведение низкотемпературного пиролиза смеси полимерных отходов, содержащей полиэтилентерефталат, полипропилен, резину автомобильных шин в присутствии катализатора, составляющего не более 5\% от массы отходов, приводит к увеличению выхода жидкотопливной фракции углеводоро- дов, а также позволяет снизить температуру проведения пиролиза на $50-100^{\circ} \mathrm{C}$.

Установлено, что катализатор оказывает влияние на формирование пористой структуры образующегося при пиролизе карбонизата. В работе Ступина А.Б. и Манько К.И. исследовалось влияние соединений переходных металлов на процесс карбонизации длиннопламенных каменных углей. Катализирующими добавками являлись оксид железа, соль железа и соль кобальта. Сырье с катализаторами тщательно перемешивали (5\% масс), затем обрабатывали спиртовыми растворами солей, сушили при температуре $105^{\circ} \mathrm{C}$ и карбонизировали при температуре $600^{\circ} \mathrm{C}$. Полученные образцы карбонизатов обладали развитой микропористой структурой [16].

Проведенный анализ научнотехнической и патентной информации по каталитическому пиролизу полимерных отходов показал, что наличие катализатора в технологическом цикле переработки отходов влияет как на качество пиролизного топлива, так и на выход и формирование пористой структуры образующегося карбонизата.

Целью настоящей работы являлось исследование влияния катализирующих добавок, в качестве которых использовали соли меди (I) и никеля (II), на формирование пористой структуры, сорбционных свойств и текстурных характеристик карбонизатов, полученных при пиролизе отходов древесностружечных плит.

\section{Экспериментальная часть}

В качестве прекурсора в экспериментальных исследованиях использовали отходы древесностружечных плит средней плотности марки Р2 с влажностью не более $13 \%$, содержащие связующее фенолформальдегидные смолы. В качестве катализаторов - соли меди (I) и никеля (II). Выбор катализаторов обусловлен возможностью ионов металлов образовывать карбонилы, что может способствовать интенсификации процессов 
термической деструкции фенолформальдегидной составляющей ДСтП.

Предварительные эксперименты и анализ научно-технической информации показали, что термическая деструкция ДСтП, фенолформальдегидных смол протекает в интервале температур 500$600^{\circ} \mathrm{C}$, поэтому исследования каталитического пиролиза проводили при температуре $600^{\circ} \mathrm{C}$ [17].

Методика проведения эксперимента. Отходы ДСтП измельчали до частиц размером 3-4 см с $^{3}$ Дисперсность материала соответствовала степени измельчения, достигаемой на промышленных роторных дробилках, используемых для переработки полимерных отходов.

Диспергированные отходы импрегнировали концентрированными растворами реагентов в определенном соотношении и выдерживали в растворах не менее 6 часов.

Процесс пиролиза проводили в лабораторной печи муфельного типа с регулируемым уровнем нагрева. Скорость подъема температур составляла 10 град/мин. Полученные карбонизаты промывали дистиллированной водой до нейтральной величины $\mathrm{pH}$ и высушивали. Параллельно проводили опыт без катализатора при неизменных прочих условиях.

Исследовалось влияние массового соотношения отход: катализатор, времени выдержки при конечной температуре на сорбционные свойства полученных образцов. При проведении исследований содержание катализатора в смеси составляло 2 и $5 \%$ от массы отходов.

Методы анализа полученных образцов карбонизатов. Сорбционные свойства полученных карбонизатов определяли по стандартным методикам, принятым в сорбционной технике: адсорбционной активности по красителю метиленовому голубому (МГ) согласно ГОСТ 4453-74 «Уголь активный осветляющий древесный порошкообразный», адсорбционной активности по йоду (ГОСТ 6217-74) «Уголь активный древесный дробленый».
Параметры пористой структуры образцов определяли на основе анализа изотерм адсорбции азота при температуpe $77 \mathrm{~K}\left(-196^{\circ} \mathrm{C}\right)$ на анализаторе сорбции газов NOVA 1200e и рассчитывали на основе уравнения теории объемного заполнения микропор ДубининаРадушкевича.

Методом рентгеновского микроанализа на сканирующем электронном микроскопе Hitachi S-3400N (Япония), оснащенном рентгеновским энергодисперсионным спектрометром NORAN, получали снимки (увеличение $1 \times 750$ ) образцов синтезированных сорбентов и определяли элементный состав поверхности в исследуемых точках.

В ходе исследований определяли $\mathrm{pH}$ водных вытяжек из полученных образцов, а также содержание в них ионов металлов. Концентрацию ионов металлов определяли методом атомно-абсорбционной спектроскопии на пламенном спектрофотометре.

Предполагалось, что проведение процесса каталитического пиролиза древесностружечных отходов может сопровождаться формированием на поверхности карбонизатов окисленных групп фенольных, альдегидных и карбоксильных, обладающих ионообменной активностью, поэтому исследовались ионообменная способность полученных образцов известным способом нейтрализации поверхностных групп гидроксидом натрия и соляной кислотой в статических условиях [18].

\section{Обсуждение результатов}

На первом этапе исследований изучалось влияние длительности выдержки при конечной температуре пиролиза $600^{\circ} \mathrm{C}(15,30$ и 60 мин) на выход и структуру карбонизата. Установлено, что в результате пиролиза формируется дробленый, структурированный карбонизат. Наибольший выход карбонизатов с достаточно низкой плотностью - 0.30-

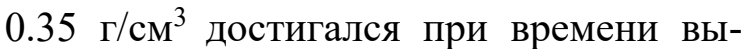
держки 30 мин. при конечной 
Таблица 1. Сорбционные свойства углеродных сорбентов, полученных из отходов ДСтП методом каталитического пиролиза

Table 1. Sorption properties of carbon sorbents obtained from chipboard wastes by catalytic pyrolysis

\begin{tabular}{|c|c|c|c|c|c|c|}
\hline $\begin{array}{c}\text { Название } \\
\text { образца }\end{array}$ & $\begin{array}{c}\text { Доля катали- } \\
\text { затора }\end{array}$ & $\begin{array}{c}\text { Выход } \\
\text { сорбента, } \\
\%\end{array}$ & $\begin{array}{c}\text { Емкость } \\
\text { по МГ, мг/г }\end{array}$ & $\begin{array}{c}\text { Емкость по } \\
\text { иноду, мг/г }\end{array}$ & $\begin{array}{c}\text { обмено- } \\
\text { емкоя } \\
\text { ммоль-экв/г, }\end{array}$ & $\begin{array}{c}\text { Катионо- } \\
\text { обменная } \\
\text { емкольсь, } \\
\text { ммоль-экв }\end{array}$ \\
\hline УС-0 & 0 & $19.42 \pm 0.97$ & $220 \pm 11$ & $337 \pm 16$ & $1.7 \pm 0.17$ & $1.3 \pm 0.31$ \\
\hline УС-Сu-1 & 0.02 & $13.34 \pm 0.67$ & $260 \pm 13$ & $503 \pm 30$ & $2.6 \pm 0.26$ & $3.8 \pm 0.38$ \\
\hline УС-Сu-2 & 0.05 & $24.2 \pm 1.2$ & $240 \pm 12$ & $620 \pm 31$ & $2.6 \pm 0.26$ & $2.2 \pm 0.42$ \\
\hline УС-Ni-1 & 0.02 & $19.73 \pm 0.99$ & $280 \pm 14$ & $619 \pm 25$ & $2.5 \pm 0.25$ & $3.7 \pm 0.37$ \\
\hline УС-Ni-2 & 0.05 & $25.7 \pm 1.3$ & $260 \pm 13$ & $660 \pm 33$ & $2.3 \pm 0.23$ & $3.7 \pm 0.37$ \\
\hline БАУ-МФ & - & - & $120 \pm 6$ & $790 \pm 35$ & $0.52 \pm 0.05$ & $1.60 \pm 0.16$ \\
\hline
\end{tabular}

температуре. Пиролиз проводили при следующих технологических параметpax: температура $600^{\circ} \mathrm{C}$, скорость нагрева печи $-10^{\circ} \mathrm{C} /$ мин. При промывке образцов водой в первых порциях элюата из образцов, импрегнированных солями меди (I), частично выщелачивались ионы меди (II) (не более 20\%). Содержание ионов никеля в элюатах, полученных при промывке образцов, содержащих никель, не превышало установленные предельно-допустимые концентрации.

В ходе проведения экспериментов были получены опытные партии карбонизатов и исследованы их сорбционные свойства. Результаты исследований представлены в таблице 1. Для проведения сравнительного анализа определены также сорбционные характеристики активированного дробленого угля марки БАУ, изготавливаемого из древесины березы методом карбонизации и активации карбонизата паром при температуре $800-850^{\circ} \mathrm{C}$

Анализ полученных данных показал, что присутствие катализаторов при пиролизе ДСтП влияет как на выход сорбента, так и на его сорбционные характеристики, причем увеличение доли каталитической добавки в исходной смеси сопровождается повышением выхода и сорбционных свойств полученных образцов.

Полученные образцы сорбентов обладают высокой осветляющей способностью, что позволяет полагать о возможности их использования для очистки сточных вод от красителей, олигомеров, нефтепродуктов. Образцы сорбентов характеризуются достаточно высокой сорбционной активностью по йоду, размер молекул которого составляет 0.54 нм, что свидетельствует о развитии микропористой структуры и способности образцов к сорбции низкомолекулярных органических соединений, например, толуола, бензола, фенола и др.

Как видно из представленных данных, по сорбционной активности полученные образцы сравнимы с активированным углем марки БАУ, но в отличие от него обладают высокой ионообменной способностью, т.е. могут быть использованы для очистки воды от ионных примесей.

Установлено, что увеличение доли каталитической добавки с 2 до 5\% не приводит к значительному повышению сорбционной активности образцов, при этом соли никеля оказывают большее влияние на сорбционные характеристики. 
Таблица 2. Параметры пористой структуры углеродных сорбентов, полученных из отходов ДСтП

Table 2. Parameters of the porous structure of carbon sorbents obtained from chipboard waste

\begin{tabular}{|c|c|c|c|c|}
\hline $\begin{array}{c}\text { Наименование пока- } \\
\text { зателя } \\
\end{array}$ & YC -0 & YC -Ni -1 & УC- $\mathrm{Cu}-1$ & БАУ-МФ \\
\hline $\begin{array}{c}\text { Суммарный объем } \\
\text { пор, } \mathrm{cm}^{3} / \Gamma\end{array}$ & 0.58 & 0.95 & 0.86 & 1.65 \\
\hline $\begin{array}{c}\text { Объем микропор } V_{\text {ми, }} \\
\mathrm{cm}^{3} / \Gamma\end{array}$ & 0.15 & 0.20 & 0.20 & 0.22 \\
\hline $\begin{array}{c}\text { Объем мезопор } V_{\text {ме }} \\
\mathrm{cm}^{3} / \Gamma\end{array}$ & 0.11 & 0.020 & 0.023 & 0.08 \\
\hline $\begin{array}{c}\text { Объем макропор } V_{\text {ма }} \\
\mathrm{cm}^{3} / \Gamma\end{array}$ & 0.32 & 0.73 & 0.64 & 1.35 \\
\hline $\begin{array}{c}\text { Характеристическая } \\
\text { энергия адсорбции, } \\
\text { кДж/моль }\end{array}$ & 20.85 & 21.22 & 22.95 & 23.1 \\
\hline $\begin{array}{c}\text { Размер полуширины } \\
\text { пор, нм }\end{array}$ & 0.62 & 0.61 & 0.56 & 0.58 \\
\hline $\begin{array}{c}\text { Средний радиус пор, } \\
\text { нм }\end{array}$ & 0.66 & 0.95 & 0.90 & 0.8 \\
\hline $\begin{array}{c}\text { Площадь поверхности } \\
\text { микропор, } \text { м }^{2} / \Gamma\end{array}$ & 452.1 & 561.7 & 564.3 & 630 \\
\hline $\begin{array}{c}\text { Площадь поверхности } \\
\mathrm{S}_{\text {Бэт, }} \mathrm{M}^{2} / \Gamma \\
\end{array}$ & 399.50 & 496.4 & 502.9 & 608 \\
\hline
\end{tabular}

Исследование параметров пористой структуры углеродных сорбентов (табл. 2) показало, что присутствие катализаторов приводит к формированию микропористой структуры карбонизатов, уменьшается доля мезопор в объеме сорбента. Природа катализатора не оказывает значительного влияния на параметры пористой структуры, но в присутствии ионов никеля образуются микропоры большего размера, что оказывает влияние на повышение осветляющей способности сорбента.

лученных образцов сравнимы с промышленной маркой древесного активированого угля БАУ-МФ.

На рис. 1 представлены электронномикроскопические снимки поверхности полученных образцов УС-0, УC-Ni-1 и УC-Cu-1 (при увеличении $1 \times 750$ ).

Образец УС-0 имеет слоистую упорядоченную структуру, подобную структуре древесины, превалирующий размер пор составляет 10-50 нм. В образцах УС$\mathrm{Ni}-2$ и УC-Cu-2 наблюдается нарушение упорядоченной структуры угля, форми-

Параметры пористой структуры по- руются более мелкие поры не-

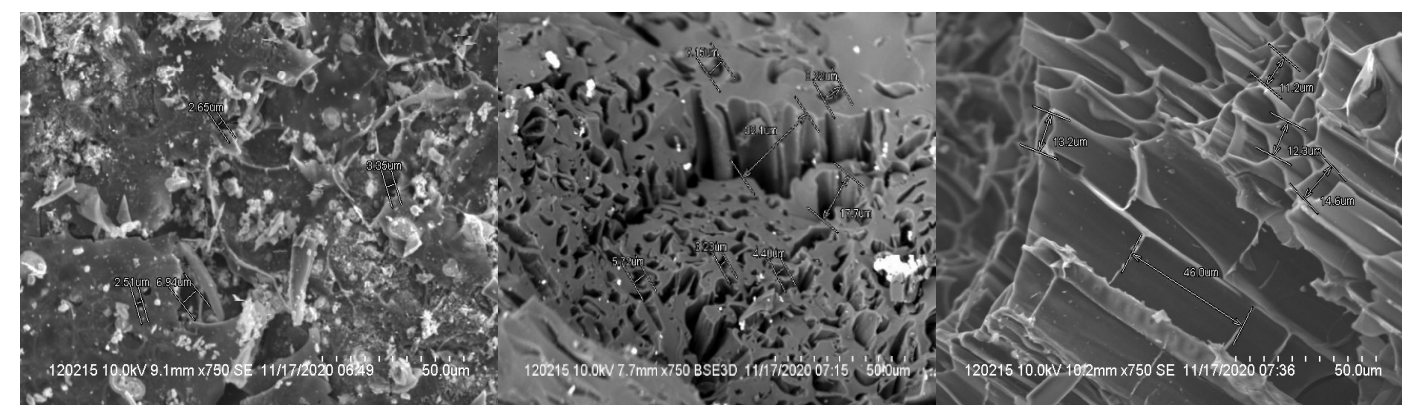

a б B

Рис. 1. Электронно-микроскопические снимки частиц и поверхности пиролизатов: a - УC-0, б - УC-Ni -1, в - УC-Cu -1

Fig. 1. Electron microscopic images of particles and surfaces of pyrolysates: $\mathrm{a}$ - US-0, b - US-Ni -1, c - US-Cu -1 
Таблица 3. Элементный состав фрагментов поверхности сорбентов

Table 3. Elemental composition of fragments of the surface of sorbents

\begin{tabular}{|c|c|c|c|c|c|}
\hline \multirow{2}{*}{ Образец } & \multicolumn{5}{|c|}{ Атомарное содержание, \% } \\
\cline { 2 - 6 } & Углерод & Кислород & Медь & Никель & Калий \\
\hline УС -0 & 90.21 & 8.79 & 0 & 0 & 0 \\
\hline УC $-\mathrm{Cu}-2$ & 45.59 & 32.96 & 6.9 & 0 & 7.1 \\
\hline УC $-\mathrm{Ni}-2$ & 54.09 & 30.11 & 0 & 8.3 & 5.7 \\
\hline
\end{tabular}

правильной формы размером 2.5 нм и меньше.

Элементный состав поверхности в исследуемых точках представлен в табл. 3

Как видно из представленных данных, при каталитическом пиролизе значительно возрастает доля кислорода в составе сорбентов, что может свидетельствовать как об образовании оксидов металлов, встраиваемых в структуру сорбента, так и о формировании поверхностных кислородсодержащих соединений (карбоксильных или фенольных групп), о чем свидетельствует повышенная ионообменная способность полученных образцов.

\section{Заключение}

Установлено, что проведение каталитического пиролиза отходов ДСтП при температуре $600^{\circ} \mathrm{C}$, скорости нагрева $10{ }^{\circ} \mathrm{C} / \mathrm{мин,} \mathrm{выдержки} \mathrm{при} \mathrm{конечной} \mathrm{тем-}$ пературе 30 мин в присутствии солей никеля (II) или меди (I) позволяет получить углеродные сорбенты по параметрам пористой структуры и сорбционным

\section{Список литературы}

1.Бесчастнов А. В. Тенденции замещения и потенциал роста: фанера. OSB. ДСП. MDF. Режим доступа: https://proderevo.net/events/ all/details/2018-11-20/45.html (дата обращения: 12.10.2020).

2. Леонович А.А. Технология древесных плит. Санкт-Петербург. Лань. 2019. 180 с.

3.Машанов А.В., Шевцов Д.Г. // Современные технологии научно-технический проzpecc. 2015.№ 1. C. 98-100.

4. Zhang J., Choi Y.S., Yoo C.G., Kim T.H. et al., ACS Sustainable Chem. Eng., 2015, Vol. 3(2), pp. 293-301. doi.org/10.1021/sc500664h свойствам сравнимым с промышленной маркой дробленого активированного угля БАУ-МФ.

Исследование сорбционных свойств полученных образцов сорбентов позволило определить оптимальную дозу катализатора при низкотемпературном пиролизе ДСтП, составляющую 2 масс.\%.

Высокое содержание кислорода в элементном составе исследуемых образцов свидетельствует о формировании поверхностных кислородсодержащих групп, способных к ионному обмену.

Полученные образцы углеродных сорбентов по сорбционной активности и осветляющей способности сравнимы с промышленными марками активированных углей и могут быть рекомендованы для очистки сточных вод от органических примесей, нефтепродуктов и красителей.

Наиболее целесообразно в качестве катализатора использовать соли никеля (II), которые встраиваются в структуру сорбента и не выщелачиваются при промывке его водой.

5. Систер В.Г., Луговой Ю.В., Косивцов Ю.Ю., Сульман Э.М. и др. // Журнал физической химии. 2011. Т. 85. № 6. С. 1192-1194.

6. Butler E., Devlin G., Meier D., McDonnell $\mathrm{K}$. // Renewable and sustainable energy reviews. 2011. Vol. 15(8). pp. 4171-4186.

7. Qinghong Kong, Ling Yang, Junhao Zhang, Yibing Cai // General Chemistry. 2017. Vol. 3(3). pp.155-158.

8. Singh R.K. Pyrolysis and catalytic cracking of municipal plastic waste for recovery of gasoline range hydrocarbons. Rourkela. 2007. Vol. 1. $46 \mathrm{p}$.

9. Rehan M., Miandad R., Barakat M.A., Ismail I.M.I. et al. // International Biodeterioration \& Biodegradation. 2017. Vol. 119. pp. 162-175. 
10. Nizami A.S., Ouda O.K., Rehan M., ElMaghraby A.M.O. et al. // Energy. 2016. Vol. 108. pp. 162-171.

11. Ratnasari D.K., Nahil M.A., Williams P.T. // Waste Manag. 2017. Vol. 124. pp. 631-637.

12. Петров М.Э., Луговой Ю.В., Косивцов Ю.Ю., Молчанов В. П. // «Разработка ресурсосберегающей технологии каталитического пиролиза отходов полимерных материалов с получением энергии и углеродных сорбентов», сборник научных трудов II Международной научной конференции, 23-24 марта 2020 г., Тверь. 2020. С. 318-324.

13. Zhou C.H., Xia X., Lin C.X., Tong D.S. et al. // Chemical Society Reviews. 2011. Vol. 40(11). pp. 5588-5617.
14. Oliveux G., Dandy L.O., Leeke G.A. // Progress in Materials Science. 2015. Vol. 72. pp. 61-99.

15.Чалов К.В. Патент РФ №2617213. 2012.

16.Ступин А.Б., Манько К.И. // Вісник донецького начіонального університету, Сер. A: Природничі науки. 2008. № 2, С. 299-301.

17. Сазанов Ю.Н., Грибанов А.В. Карбонизация полимеров. Санкт-Петербург. НОТ. 2013. $296 \mathrm{c}$.

18. Комисаренков А.А., Федорова О.В. Сорбционные технологии. Определение свойств сорбентов. Санкт Петербург. 2015. $44 \mathrm{c}$.

\title{
Influence of catalytic additives on the process of the production of carbon sorbents from chipboard waste
}

\author{
(C) 2021 Glushankova I.S., Atanova A.S. \\ Perm National Research Polytechnic University, Perm
}

\begin{abstract}
The study presents the results of the research devoted to the processing of large-tonnage polymer chipboard waste (hereinafter referred to as chipboard) by the low-temperature pyrolysis method in the presence of catalytic additives: transition metal salts $\left(\mathrm{Cu}^{+}, \mathrm{Ni}^{2+}\right)$ and potassium hydroxide. The study analyses the scientific and technical information of known methods for processing polymer waste and methods of the production of carbon sorbents using various reagents. The aim of this study was the investigation of the effect of catalytic additives of transition metal salts $\left(\mathrm{Cu}^{+}, \mathrm{Ni}^{2+}\right)$ and potassium hydroxide on the physicochemical, sorption and textural characteristics of pyrolysates obtained from polymer chipboard waste.
\end{abstract}

The authors present the results of laboratory studies using modern analytical measurement methods and equipment. The analysis of the porous structure of pyrolysates was based on nitrogen adsorption $(77 \mathrm{~K})$ using a Quantachrome NOVA 4200e gas sorption analyser. The total content of metals was measured based on the atomic absorption according to the M-02Vd/2001 method using a KVANT-2MT flame atomic absorption spectrophotometer. The X-ray microanalysis method using a Hitachi S-3400N (Japan) scanning electron microscope, equipped with a NORAN X-ray energy dispersive spectrometer was used to obtain images at a magnification of x1000. Also, for research, we used standard techniques adopted in adsorption technology: spectrophotometric, titrimetric, potentiometric methods, etc. The study presents the results of thermochemical utilization of polymer chipboard waste, where the parameters of the pyrolysis process were established. The optimal mass ratio of chipboard waste: catalyst was 1:0.02, pyrolysis temperature was $600-700^{\circ} \mathrm{C}$, at a rate of 10-12 deg/min, exposure time was 30-60 min. In this study, the influence of the pyrolysis conditions in the presence of $\mathrm{KOH}$ and without it on the formation of the porous structure and the sorption properties of the obtained samples were investigated. The maximum practical yield was determined for chipboard: $\mathrm{KOH}$ (1:0.02) $-34 \%$, Sorption characteristics - sorption of iodine $-763 \pm 25 \mathrm{mg} / \mathrm{g}$, sorption of $\mathrm{MG}-200 \pm 11 \mathrm{mg} / \mathrm{g}$.

It was found that the introduction of catalysts affects the practical yield, sorption properties and parameters of the porous structure. Thus, the introduction of the catalysts to the $\mathrm{Cu}^{+}$and $\mathrm{Ni}^{2+}$ system allowed increasing the product yield from 20 to $25 \%$. The introduction of a nickel catalyst into the chipboard: $\mathrm{Ni}^{2+}$ (1:0.02) system allowed increasing the sorption of iodine by pyrolysates by $40 \%$. The volume of micropores was $0.203 \mathrm{~cm}^{3} / \mathrm{g}$, the surface area of micropores was $562 \mathrm{~m}^{2} / \mathrm{g}$. Scanning electron microscopy showed that pyrolysates without catalysts had a layered ordered structure similar in properties to wood, the pore size was $10-50 \mathrm{~nm}$. After the introduction of catalysts, the impairment of the structure of coals was observed; in chipboard: $\mathrm{Ni}^{2+}(1: 0.02)$ samples and chipboard: under the influence of $\mathrm{Cu}^{2+}(1: 0.05)$ smaller pores of irregular shapes from $2.5 \mathrm{~nm}$ in size were formed. Based on the results of the study, it can be concluded that the introduction of catalytic additives of transition metal salts $\left(\mathrm{Cu}^{+}, \mathrm{Ni}^{2+}\right)$ and potassium hydroxide affects the physi- 
cochemical properties, the porous structure of pyrolysates and their textural characteristics. The proposed method allows obtaining pyrolysates, possessing sorption properties similar in characteristics to industrial brands of charcoal of BAU-MF type in one stage.

Keywords: chipboard waste, catalytic pyrolysis, catalysts, porous structure, electron microscopic analysis, pyrolysates.

\section{References}

1. Beschastnov A.V. Tendencii zameshheniya ipotencial rosta: fanera, OSB, DSP, MDF. availableat: https://proderevo.net/events/all/ details/2018-11-20/45. (accessed 12.10.2020).

2. Leonovich A.A. Tehnologiya drevesny`xplit. St Peterburg, Lan`, 2019, 180 p.

3. Mashanov A.V., Shevczov D.G., Sovremenny etexnologiinauchno-texnicheskij progress, 2015, Vol.1, No 1, pp. 98-100.

4. Zhang J., Choi Y.S., Yoo C.G., Kim T.H. et al., ACS Sustainable Chem. Eng., 2015, Vol. 3(2), pp. 293-301.

5. Sister V.G., Lugovoj Yu.V., Kosivczov Yu.Yu., Sul'man E'.M. et al., Zhurnal fizicheskoj khimii, 2011, Vol. 85, No 6, pp. 1192-1194.

6. Butler E., Devlin G., Meier D., McDonnell $\mathrm{K}$., Renewable and sustainable energy reviews., 2011, Vol. 15(8), pp. 4171-4186, doi.org/10.1039/C1CS15124J 11.

7. Qinghong Kong, Ling Yang, Junhao Zhang, Yibing Cai, General Chemistry, 2017, Vol. 3(3), pp.155-158.

8. Singh R.K. Pyrolysis and catalytic cracking of municipal plastic waste for recovery of gasoline range hydrocarbons, Rourkela, 2007, Vol. $1,46 \mathrm{pp}$.

9. Rehan M., Miandad R., Barakat M.A., Ismail I.M.I. et al, International Biodeterioration

Глушанкова Ирина Самуиловна - д.т.н., профессор кафедры «Охрана окружающей среды», Пермский национальный исследовательский политехнический университет, Пермь

Атанова Анна Сергеевна - аспирант кафедры «Охрана окружающей среды», Пермский национальный исследовательский политехнический университет, Пермь
\& Biodegradation, 2017, Vol. 119, pp. 162175 .

10. Nizami A.S., Ouda O.K., Rehan M., ElMaghraby A.M.O. et al. Energy, 2016, Vol. 108, pp. 162-171.

11. Ratnasari D.K., Nahil M.A., Williams P.T., Waste Manag., 2017, Vol. 124, pp. 631637.

12. Petrov M.E., Lugovoj Yu.V., Kosivczov Yu.Yu., Molchanov V.P., "Razrabotka resursosberegayushhej texnologii kataliticheskogo piroliza otxodov polimerny'x materialov $\mathrm{s}$ poluchenieme' nergiiiuglerodny'x sorbentov", Proceedings of the II International Conference, March 23-24, 2020, Tver', 2020, pp. 318-324.

13. Zhou C.H., Xia X., Lin C.X., Tong D.S. et al., Chemical Society Reviews, 2011 Vol. 40(11), pp. 5588-5617.

14. Oliveux G., Dandy L.O., Leeke G.A., Progress in Materials Science, 2015, Vol. 72, pp. 61-99.

15. Chalov K.V. Patent RF, No 2617213, 2012.

16. Stupin A.B., Man'ko K.I., Visnik donecz 'kogo naczional nogo universitetu, Ser. A: Prirodnichinauki, 2008, No 2, pp. 299-301.

17. Sazanov Yu.N., Gribanov A.V. Karbonizaciyapolimerov, St. Peterburg, NOT, 2013, $296 \mathrm{p}$.

18. Komisarenkov A.A., Fedorova O.V. Sorbcionny`e texnologii. Opredelenie svojstv sorbentov, Saint Petersburg, 2015, Vol. 1, p. 44.

Glushankova Irina S. - Doctor of Technical Sciences, Professor of Environmental Protection Department, Perm National Research Polytechnic University, Perm, e-mail: irina_chem@mail.ru

Atanova Anna S. - Graduate student of Environmental Protection Department, Perm, National Research Polytechnic University, Perm 